\title{
How much "surgical effort" should be added to HIPEC?
}

\author{
Quanto esforço cirúrgico deveria ser associado à HIPEC?
}

Thales Paulo Batista', Levon Badiglian-Filho², Glauco Baiocchi²

\begin{abstract}
Hyperthermic intraperitoneal chemotherapy (HIPEC) has emerged as a main comprehensive treatment of malignancies on the peritoneal surface and thus, it has been considered a promising treatment option for a peritoneal-borne disease such as ovarian cancer. The rationale for using HIPEC is based on the direct cytotoxicity of hyperthermia for malignant cells, the enhancement of this cytotoxicity by anticancer drugs, and the pharmacokinetic advantages of the i.p. route for chemotherapy. It could also reduce the mechanisms of cellular chemo-resistance and induce an efficient anticancer immune response. This technique is delivered intraoperatively, avoiding the need for implantation of peritoneal access devices and thereby reducing catheter-related morbidity and tolerance issues. Despite these potential advantages of HIPEC, there was no clear evidence from randomized controlled trials to advocate this approach as a standard therapy for patients suffering from advanced ovarian cancer.
\end{abstract}

Recently, van Driel et al.(1) presented the first well-designed study addressed to provide some clarity to this issue. In this multicenter, open-label, phase III trial, 245 patients with at least stable disease after three cycles of neoadjuvant chemotherapy (NACT) were randomly assigned to undergo interval cytoreductive surgery with or without HIPEC (i.e.: CDDP $100 \mathrm{mg} / \mathrm{m} 2$, for 90 minutes at $40^{\circ} \mathrm{C}$ ). Three further cycles of carboplatin and paclitaxel were given postoperatively. With this comprehensive approach, the authors found a median RFS of 14.2 vs. 10.7 months favoring the HIPEC group ( $\mathrm{HR}=0.66,95 \% \mathrm{Cl} 0.50-0.87 ; \mathrm{p}=0.003$ ). Median OS was 45.7 months in the HIPEC group and 33.9 months in the non-HIPEC group $(\mathrm{HR}=0.67,95 \% \mathrm{Cl} 0.48-0.94 ; \mathrm{p}=0.02)$. Also, the incidence of major adverse events was similar in the two groups and no significant differences in health-related quality-of-life outcomes over time were observed.

1. Department of Surgery/Oncology, Instituto de Medicina Integral Professor Fernando Figueira, Recife, PE, Brazil; Department of Surgery, Universidade Federal de Pernambuco, Recife, PE, Brazil.

2. Department of Gynecology, A.C. Camargo Cancer Center, São Paulo, SP, Brazil.

Conflict of Interest Statement: All the authors declare no conflicts of interest, financial support or disclaimers related to this letter to the editor. Funding Source: None.

Corresponding author: Thales P. Batista. Rua Pio IX, 435, Ap. 701/B - Recife, PE, Brazil. Phone: +55 (81) 98886-1203, Zip code: $50710-265$.

E-mail: t.paulo@outlook.com

Received on: 2018 April 5 | Accepted on: 2018 May 16

DOI: $10.26790 / B J O 20181448$ A218 
As pointed by Spriggs and Zivanovic in an accompanying editorial survival outcomes in that trial were consistent with previous trials such as the EORTC55971 study, but were shorter than currently expected. No matter what this may result from enrollment of high tumor burden patients, the "surgical effort" appeared to be low based on the duration of procedures. Herein, the median duration of surgery was 192 minutes (IQR, 153 to 251) vs. 338 minutes (IQR, 299 to 426), despite surgery has been extended by about 2 hours due to addiction of HIPEC. (1) These lengths of surgeries were lower than what were reported in the NACT group of the SCORPION and JCOG0602 trials (i.e.: median duration of 275 and 302 minutes; respectively), for example; ${ }^{(3)}$ whereas the survivals outcomes were quite similar to those reported in the feasibility study of NACT followed by interval cytoreductive surgery named JCOG0206 trial (i.e.: PFS and OS of 14 and 45 months, respectively), in which the median operative time was 330 (130-735) minutes. $^{(4)}$ In our ongoing trial exploring HIPEC as a short-course (i.e.: 30 minutes) regimen in a similar study design, ${ }^{(5)}$ the current operative time is 430 (235-865) minutes, with a median time spent during perfusion of only 50.5 minutes. Previously, our experience with NACT (including patients with suboptimal CRS) had reached median PFS and OS of 17.6 and 41.6 months, respectively. ${ }^{(6)}$

Despite all the enthusiasm arising from the publication of this very important study, ${ }^{(7)}$ we feel that a further "surgical effort" should be added to a comprehensive treatment involving HIPEC, since the surgical component of the binomium CRS plus HIPEC is the well-known element that most contributes to improve outcomes in ovarian cancer. ${ }^{(8)}$ Additional skepticism from us involves the possibility of increased morbidity and mortality with the use of a 90 minutes in length regimen of HIPEC in less experienced centers.

\section{REFERENCES}

1. van Driel WJ, Koole SN, Sikorska K, Schagen van Leeuwen $\mathrm{JH}$, Schreuder HW, Hermans $\mathrm{RH}$, et al. Hyperthermic intraperitoneal chemotherapy in ovarian cancer. N Engl J Med. 2018;378(3):230-40.

2. Spriggs DR, Zivanovic O. Ovarian cancer treatment - are we getting warmer? N Engl J Med. 2018;378(3):293-4.

3. Wright AA, Bohlke K, Armstrong DK, Bookman MA, Cliby WA, Coleman RL, et al. Neoadjuvant Chemotherapy for Newly Diagnosed, Advanced Ovarian Cancer: Society of Gynecologic Oncology and American Society of Clinical Oncology Clinical Practice Guideline. J Clin Oncol. 2016;34(28):346073.

4. Onda T, Kobayashi H, Nakanishi T, Hatae M, Iwasaka T, Konishi I, et al. Feasibility study of neoadjuvant chemotherapy followed by interval debulking surgery for stage III/IV ovarian, tubal, and peritoneal cancers: Japan Clinical Oncology Group Study JCOG0206. Gynecol Oncol. 2009;113(1):57-62.
5. Batista TP, Carneiro VC, Tancredi R, Teles AL, Badiglian-FiIho L, Leão CS. Neoadjuvant chemotherapy followed by fast-track cytoreductive surgery plus short-course hyperthermic intraperitoneal chemotherapy (HIPEC) in advanced ovarian cancer: preliminary results of a promising all-in-one approach. Cancer Manag Res. 2017;9:869-78.

6. da Costa AA, Valadares CV, Baiocchi G, Mantoan H, Saito A, Sanches $S$, et al. Neoadjuvant chemotherapy followed by interval debulking surgery and the risk of platinum resistance in epithelial ovarian cancer. Ann Surg Oncol. 2015;22 Suppl 3:S971-8.

7. Stirrups R. HIPEC improves survival in stage III epithelial ovarian cancer. Lancet Oncol. 2018 Jan 26. pii: S14702045(18)30065-2.

8. Kusamura S, Sinukumar S, Baratti D, Guaglio M, Guadagni S, Deraco M. Cytoreductive surgery and HIPEC in the first line and interval time points of advanced epithelial ovarian cancer. Indian J Gynecol Oncol. 2017;15(Suppl 1):S11-S20. 